\title{
A besta de sete cabeças e seus antecedentes em textos da cultura antiga
}

\section{The seven-headed beast and its antecedents in texts of the ancient culture}

\begin{abstract}
Resumo
O artigo analisa a metáfora da besta de sete cabeças e sua intertextualidade no Apocalipse de João e textos antigos egípcios e mesopotâmicos bem como com o Antigo Testamento. Fundamenta-se no conceito de metáfora, segundo Lakoff e Johnson; de texto da cultura, intertextualidade e semiosfera, oriundos da Semiótica da Cultura, de Lotman; e do monstro como representação simbólica de uma alteridade grotesca, segundo Cohen. Parte da pressuposição de que elementos semióticos e conceituais, plantados na memória das culturas, permitem o entrecruzamento dos textos de diferentes épocas e lugares. Além do texto bíblico em que animais monstruosos são usados como representação de poderes opositores, a metáfora da besta é analisada em suas conexões semióticas com textos antigos nos quais também se verifica a construção de figuras monstruosas de sete cabeças, como a Paleta de Narmer de 3100 a.C. e o Cilindro de Tell Asmar de 2200 a.C., entre outros. Essas conexões indicam que o texto apocalíptico bíblico não está isolado das culturas de seu tempo. Permitem também enxergar as narrativas proféticas do Apocalipse como texto da cultura, capaz de dialogar com uma rede de outras narrativas.
\end{abstract}

Palavras-chave: besta de sete cabeças, metáfora, mitologia.

\begin{abstract}
This article analyzes the metaphor of the seven-headed beast and its intertextuality in the Apocalypse of John and ancient Egyptian and Mesopotamian texts as well as with the Old Testament. It is based on the concepts of metaphor, according to Lakoff and Johnson; the concepts of texts of culture, intertextuality, and semiosphere, from Lotman's Semiotics of Culture; and the monster as a symbolic representation of a grotesque alterity, according to Cohen. It starts from the assumption that some linguistic and conceptual elements, settled in the memory of cultures, allow the intertwining of texts of different times and places. In addition to the biblical text in which monstrous animals are used as representations of opposing powers, the metaphor of the beast is taken in its semiotic connections with ancient texts in which also is verified a building of seven-headed monsters, like the Palette of Narmer from 3100 B.C. and the Cylinder of Tell Asmar from 2200 B.C., among others. These connections indicate that the biblical apocalyptic text is not isolated from the cultures of its time. They also allow us to see the prophetic narratives of the Apocalypse as a text of culture which is able to dialogue with a network of other narratives.
\end{abstract}

Keywords: seven-headed beast, metaphor, mythology.

\footnotetext{
Artigo submetido em 10 de agosto de 2017 e aprovado em 07 de dezembro de 2017.

* Doutor em Ciências pela Escola de Comunicação e Artes (USP) e doutorando em Ciências da Religião pela Universidade Metodista de São Paulo. É docente da Faculdade de Teologia do UNASP-EC. E-mail: vanderlei.dorneles@ucb.org.br.
}

Horizonte, Belo Horizonte, v. 15, n. 48, p. 1423-1445, out./dez. 2017 - ISSN 2175-5841 


\section{Introdução}

No livro do Apocalipse são descritos três símbolos caracterizados como monstros de sete cabeças: o dragão vermelho (Ap 12:3), a besta semelhante a leopardo (Ap 13:1) e a besta escarlate (Ap 17:3). Os elementos visuais e anatômicos desses monstros apocalípticos são os recursos de uma linguagem metafórica empregada na descrição de conflitos de natureza cultural, política e religiosa.

As duas características principais (as sete cabeças e os dez chifres) indicam que, no Apocalipse, apesar de descritos em três relatos diferentes, esses monstros são paralelos ou recapitulativos. Kistemaker (2001, p. 464) afirma que "a besta escarlate de sete cabeças e dez chifres é descrita nos mesmos termos do dragão vermelho" e da "besta que sobe do mar". Collins (2001, p. 32) sustenta a natureza recapitulativa dos principais ciclos de visões do livro. Mounce (1998, p. 32) aceita que certas unidades paralelas são inegáveis no Apocalipse. Por sua vez, Johnsson (2011, p. 886, 887) entende que as narrativas apocalípticas são paralelas e que elas "recapitulam e ampliam o assunto já apresentado", acrescentando "detalhes ausentes no relato anterior". Nessa linha, embora se reconfigure em cada uma das descrições com novos detalhes semióticos, esse elemento monstruoso do Apocalipse parece ser um único e mesmo símbolo.

Alguns aspectos linguísticos e descritivos reforçam a ideia de um paralelismo entre os três relatos. As mesmas palavras gregas kephalas hepta e kérata déka são usadas em referência às sete cabeças e aos dez chifres (12:3; 13:1; 17:3, 7, 12, 16). Os combates são descritos com o mesmo substantivo grego pólemos e o verbo poleméo (12:7, 17; 13:7; 17:14). Os cristãos são chamados de hagiós, "santos" (13:7, 10; 17:6). "Miguel" é mencionado em 12:7 e sugerido em 13:4. Os três relatos tratam de um combate seguido de vitória/derrota $(12: 9 ; 13: 3,10 ; 17: 14,16)$.

A figura monstruosa descrita nesses três diferentes textos tem desafiado os intérpretes ao longo do tempo. O que o texto apocalíptico comunica com o emprego dessa metáfora? Que textos da cultura antiga acessíveis ao autor podem ter 
influenciado suas narrativas? Essas questões servem de ponto de partida para este estudo cujo objetivo é tentar identificar outros monstros do texto bíblico, da cultura popular e da arte antiga e compreender seu sistema de representação a fim de prover um panorama cultural para esses símbolos descritos no Apocalipse.

\section{0 monstro nos textos da cultura}

O estudo das figuras monstruosas nos textos da cultura demanda suporte teórico diverso. Para os propósitos deste estudo, são relevantes os conceitos de metáfora, intertextualidade e semiosfera.

Numa visão tradicional as metáforas são apenas elementos de linguagem. Porém, Lakoff e Johnson (2003, p. 54) propõem que elas servem como instrumentos que "estruturam o sistema conceitual das culturas". Para eles, as metáforas são sempre "conceituais" e estão entre os principais meios de compreensão da realidade. Segundo eles, as metáforas chegam a exercer "um papel central na construção da realidade social e política” nas diferentes culturas (2003, p. 160). Isso significa dizer que as metáforas são recursos não só para descrever, mas para pensar e estruturar a compreensão da realidade. Quando algum aspecto da realidade desafia nosso sistema conceitual, as metáforas podem ser empregadas na tentativa de compreender o que está além de nós. Elas nos ajudam a pensar e expressar o que "não podemos compreender totalmente: os sentimentos, a experiência estética, práticas morais e consciência espiritual" (2003, p. 194).

Lakoff e Johnson (2003, p. 6) afirmam ainda que "a essência da metáfora é compreender e experimentar uma coisa em termos de outra”. Nesse caso, aplicados aos símbolos apocalípticos em questão, o conceito de metáfora desses autores implica que os monstros, como figuras ou metáforas que não encontram equivalentes em nossa realidade, são um constructo para representar algo não pertencente ao nosso sistema conceitual, algo que não faz parte de nossa realidade; uma alteridade que causa estranheza. 
Uma vez que partimos da hipótese de que a metáfora do monstro de sete cabeças existe em outros textos e que, na verdade, é recorrente em textos de diferentes culturas, o conceito de intertextualidade também se torna bastante útil. $\mathrm{O}$ termo provém dos estudos literários recentes, mas o conceito pode ser mais antigo. Com base na ideia de dialogismo de Bakhtin, Julia Kristeva (1969, p. 64) afirma que "todo texto se constrói como um mosaico de citações, todo texto e absorção e transformação de um outro texto”. Isso implica dizer que todo autor ao produzir um texto necessariamente entrelaça nele recortes, fragmentos e figuras de textos diversos com os quais tem estado em contato. Isso faz justiça ao significado de "texto" que vem do verbo latim tecere, "tecer" ou "entretecer". Assim, todo texto se apresenta como uma complexa rede tecida com fragmentos de textos anteriores.

Sloan e Newman (2002, p. 58-59) propõem que o texto bíblico, a exemplo dos textos da cultura, também resulta de processos intertextuais complexos, e que intertextualidade pode ser entendida como "o engaste de fragmentos, imagens e ecos de um texto dentro de outro".

Como se processa a dinâmica da intertextualidade e como os textos chegam a constituir encadeamentos linguísticos e semânticos?

Esta é uma questão central na compreensão da origem da metáfora da besta. Na Semiótica da Cultura, de origem russa, a memória é compreendida como o agente estratégico no processo da intertextualidade. A memória é a instância em que os textos antigos são conservados e de onde se articula seu processo de semiose. Ela é constituída de linguagens e textos. O texto, para Lotman (2000, p. 18), é o "condensador" da memória. Para ele, a memória é um reservatório dinâmico que conserva, transmite e gera textos. Lotman (1996, p. 157) concebe a cultura como "uma inteligência coletiva e uma memória coletiva", na qual os textos estão organizados em certa hierarquia. Lotman (1996, p. 23, 24) afirma que os textos e as linguagens da cultura habitam esse espaço semiótico, que ele chamou de "semiosfera". Nesse espaço as linguagens e os textos estão num constante processo 
de entrecruzamentos para a produção de novos textos. A semiosfera, portanto, é “um conjunto de textos distintos e de linguagens entrelaçados uns com os outros”. Nessa linha de pensamento, a metáfora da besta de sete cabeças funciona como um elemento encadeador dos textos da cultura, como um tipo arquétipo compartilhado por diferentes sistemas da cultura.

Esse entrelaçamento entre os textos de diferentes culturas, dentro da semiosfera, permite que cada cultura e cada sistema opere dialogicamente frente aos demais, numa troca constante de informação sígnica e semiótica através das fronteiras. Por meio desse entrelaçamento dinâmico não só as linguagens dos textos são constantemente compartilhadas entre as culturas, mas também certos conceitos e elementos culturais incorporados nessas linguagens.

Dada a complexidade do símbolo da besta ou monstro de sete cabeças no texto do Apocalipse e sua ocorrência em diversos textos da cultura, consideramos também apropriado ver esse símbolo à luz das propostas de Cohen (1996, p. 4) acerca da semântica do monstro nos textos da cultura. Para este pesquisador, além de metáfora, o monstro é um texto ou signo, em primeiro lugar. Ele não tem vida própria nem pode ocorrer independentemente de uma necessidade de nomear algo. Nesse sentido, na linguagem da semiótica, o monstro é um texto, ou arranjo de signos, para ser lido e interpretado. Ele nasce de um momento ou circunstância cultural incertos, e da necessidade de nomear o inominável nesse contexto. Assim, “o corpo monstruoso é pura cultura”. Como constructo ou projeção, "o monstro existe somente para ser lido", sendo apenas uma representação, "um símbolo que procura um intérprete, um glifo que procura um sacerdote ou vidente". Com base nisso, Cohen conclui que, "como uma letra na página, o monstro significa outra coisa e não ele mesmo".

Esses conceitos teóricos tornam bastante apropriada a leitura dos monstros apocalípticos como metáforas e símbolos de um sistema de representação da alteridade, daquilo que está além da fronteira e que não é próprio nem familiar. 


\section{A metáfora da besta no Antigo Testamento}

Um primeiro aspecto das bestas é que elas não são inéditas no Apocalipse. Em diferentes contextos, metáforas monstruosas semelhantes foram empregadas na descrição de situações de tensões e conflitos entre os israelitas e seus vizinhos.

O Apocalipse emprega a palavra grega theríon ("besta") 38 vezes para os símbolos monstruosos. O termo é usado pela versão grega do Antigo Testamento para traduzir a palavra hebraica chay, que se refere a animais e feras selvagens ( $\mathrm{Lv}$ 11:27; Sl 50:10; 79:2; Is 56:9; Jr 12:9). No entanto, no Antigo Testamento grego, a palavra theríon também é usada como metáfora para representar os inimigos políticos de Israel e Judá, como em Ezequiel 34. Falando sobre a restauração do cativeiro babilônico, o profeta diz que as ovelhas de Israel estavam sendo "devoradas" pelas "bestas" (thería) nos "países" que as escravizavam. Ele não usa a palavra "besta" em referência a leões e feras selvagens que atacassem os judeus, mas às nações inimigas, que, como feras selvagens, procuravam devorá-los. No v. 25, o Deus de Judá afirma: "farei com elas um concerto de paz", e "acabarei com a besta ruim [theríon] da terra" (ARC). Neste versículo, Ezequiel emprega a palavra hebraica chay, no singular, a qual é vertida no texto grego para o plural thería, "bestas". Por isso, a ARA utiliza o plural seguindo a versão grega, e a ARC segue o texto hebraico, traduzindo o singular "besta".

Em resultado dessa ação contra a "besta", Deus garante: "E saberão que eu sou o Senhor, quando eu quebrar as varas do seu jugo e as livrar das mãos dos que as escravizam. Já não servirão de rapina aos gentios, e as feras da terra nunca mais as comerão" (v. 27, 28). Novamente no v. 28 , o texto hebraico usa o substantivo no singular, e a ARC traduz: "não servirão mais de rapina aos gentios, e a besta-fera [heb. chay] da terra nunca mais as comerá" (Ez 34:28). Neste texto, portanto, Ezequiel se refere ao Egito, Assíria e Babilônia, nações gentílicas que oprimiam os judeus, com a metáfora da besta. O fim de cativeiro de Judá, portanto, é referido como resultado de Deus quebrar o "jugo" de servidão com a destruição da "besta”. 
Isaías fala do fim do cativeiro, em paralelo com Ezequiel, com as seguintes palavras: "Naquele dia, o Senhor tornará a estender a mão para resgatar o restante do seu povo, que for deixado, da Assíria, do Egito, de Patros, da Etiópia, de Elão, de Sinar [Babilônia], de Hamate e das terras do mar” (Is 11:11, 12). Miqueias também fala do fim do cativeiro, incluindo Egito, Assíria e Babilônia, como opressores de Judá (Mq 7:12).

Além da palavra theríon, o Apocalipse emprega 13 vezes o substantivo grego drákon, "dragão", e quatro vezes ophis, "serpente”, de forma intercambiável para descrever monstros simbólicos. Por sua vez, essas figuras também são empregadas no Antigo Testamento. Curiosamente, a metáfora do dragão é usada em referência ao Egito e a Babilônia. Falando sobre o êxodo, o salmista afirma: "Tu [Senhor] dividiste o mar pela tua força; quebraste a cabeça dos monstros das águas. Fizeste em pedaços as cabeças do Leviatã, e o deste por mantimento aos habitantes do deserto" (Sl 74:13, 14, ARC). Neste texto, o salmista emprega o termo hebraico tannyin, traduzido por "monstros das águas" e na versão grega por drákon; e utiliza o termo hebraico livyathan, traduzido por "Leviatã” e na versão grega também por drákon. Portanto, nessa linguagem poética tannyin e livyathan são usados como metáforas intercambiáveis em referência ao Egito.

Nesse salmo, tanto no v. 13 quanto no 14, o salmista usa a palavra hebraica ro'sh ("cabeças"), no plural, no que é seguido pela versão grega. Nesse caso, no paralelismo, o salmista está dizendo que Deus, no êxodo, quebrou as cabeças do dragão. O Egito, portanto, é referido aqui com a figura do dragão de múltiplas cabeças. O livro de Isaías também se refere ao Egito, no contexto do êxodo, com a figura do tannyin, ou "dragão" (ARC), como tendo sido ferido pelo Senhor (Is 51:9, 10); o mesmo é feito por Ezequiel (Ez 29:3; 32:2).

O fato de o monstro figurativo ser referido pelo salmista como tendo múltiplas cabeça é significativo, ao considerar esses textos como intertextos para a metáfora do dragão e da besta de sete cabeças descritos no Apocalipse. Além disso, o fato de 
as cabeças do monstro serem quebradas pelo Senhor faz lembrar Genesis 3:15, com a promessa de que o filho da mulher "esmagaria" a cabeça da "serpente", do hebraico nachash (Gn 3:15; vertido na LXX como ophis, metáfora também usada no Apocalipse).

Além do Egito, também Babilônia é chamada de tannyin (drákon, na LXX), o qual esmagou Judá, mas que seria destruído pelo Senhor (Jr 51:34, 36, 37). Esta, portanto, é a segunda nação opressora de Judá retratada com o emprego da metáfora desse monstro figurativo. Na mesma perspectiva do reino messiânico como o tempo da libertação de todos os opressores, o texto de Isaías ainda diz: "Naquele dia, o Senhor castigará com a sua dura espada, grande e forte, o dragão, serpente veloz, e o dragão, serpente sinuosa, e matará o monstro que está no mar” (Is 27:1). O profeta emprega aqui o termo livyathan (drákon, na LXX), e tannyin (drákon, na LXX) e os interpreta como sendo a "serpente", que é nachash (ophis, na LXX), os dois termos gregos empregados no Apocalipse.

Diante do uso das metáforas da besta e do dragão no Antigo Testamento pode se falar de uma intertextualidade bastante clara entre as narrativas do Apocalipse e os textos do Antigo Testamento. Na linguagem de Lotman, a memória aqui funciona como um reservatório de textos, os quais exercem uma função encadeadora na produção de novos textos. Pela ação da memória, metáforas e linguagens carregam certos conceitos e os disseminam entre textos de diferentes épocas, produzindo e reproduzindo novos sentidos os quais caracterizam esses textos como entrecruzados ou encadeados pelas metáforas que utilizam. Nesses textos de diferentes épocas, a metáfora do monstro é empregada para retratar poderes inimigos, os quais ameaçavam a sobrevivência dos judeus.

No entanto, a natureza dinâmica da semiosfera nos leva a outra questão: seriam só os textos da cultura judaico-israelita que estariam entrecruzados nesse compartilhamento das linguagens e metáforas monstruosas na descrição de poderes opressores? 


\section{A metáfora da besta na cultura antiga}

Fora do contexto bíblico, há diversas figuras monstruosas de sete cabeças ou mais as quais também se apresentam como recursos de uma linguagem metafórica na representação de inimigos, opositores, povos estranhos de línguas e culturas diferentes. Aune (1997, p. 667) diz que narrativas de combate entre um herói e seu adversário pela soberania eram bastante difundidas no mundo antigo. "Nos mitos de combate o antagonista é frequentemente retratado como um monstro, serpente ou dragão”. Entre esses monstros antigos de múltiplas cabeças citam-se a hidra vencida por Hércules e Iolã, na mitologia grega; o monstro tipo dragão derrotado por Ninurta, na mitologia suméria; o Leviatã também da mitologia suméria retratado no Cilindro de Tell Asmar; e há ainda a chamada Paleta de Narmer, que emprega a figura de um monstro de sete cabeças para retratar um rei inimigo do Alto Egito.

Consta que um dos grandes feitos de Hércules foi derrotar a hidra de sete/nove cabeças, no que contou com a ajuda de seu sobrinho Iolã. Cada cabeça cortada pelo herói voltava a crescer, até que Iolã entrou na batalha e tratava de cauterizar com fogo o lugar daquela cabeça. Com isso Hércules conseguiu vencer o monstro cabeça após cabeça. Essa narrativa já existia por volta do sexto século a.C. (cf. ROMAN E ROMAN, 2010, p. 214). Há também o monstro de sete cabeças destruído pelo herói/deus Ninurta. A chamada "Ninurta e o dragão de sete cabeças" é uma arte em embutimento que vem do período sumério dinástico anterior (cerca de 2800-2600 a.C.). Está no Museu das Terras Bíblicas em Jerusalém. Representa o rei Ninurta em luta contra um monstro de sete cabeças. Ninurta era um famoso caçador e guerreiro, e seus instrumentos incluíam arco, flechas e espada. Consta que Ninurta matou sete monstros heroicos. Um dos monstros teria sido um esplêndido dragão/serpente de sete cabeças. Esta criatura mitológica pode ser a versão suméria da hidra grega (cf. FORD, 2016, p. 27-29) 


\begin{tabular}{|c|c|}
\hline $\begin{array}{c}\text { Imagem 1: } \\
\text { Hércules e Iolã derrotam a hidra }\end{array}$ & $\begin{array}{c}\text { Imagem 2: } \\
\text { Ninurta e o monstro de sete } \\
\text { cabeças }\end{array}$ \\
\hline 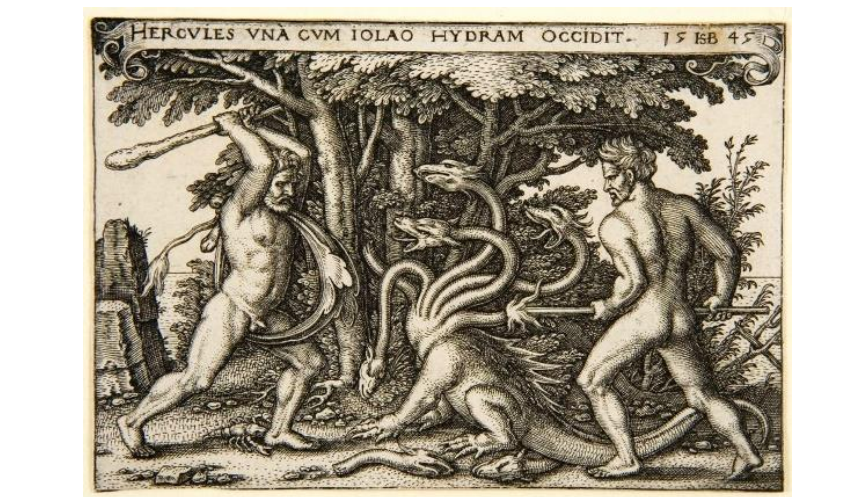 & 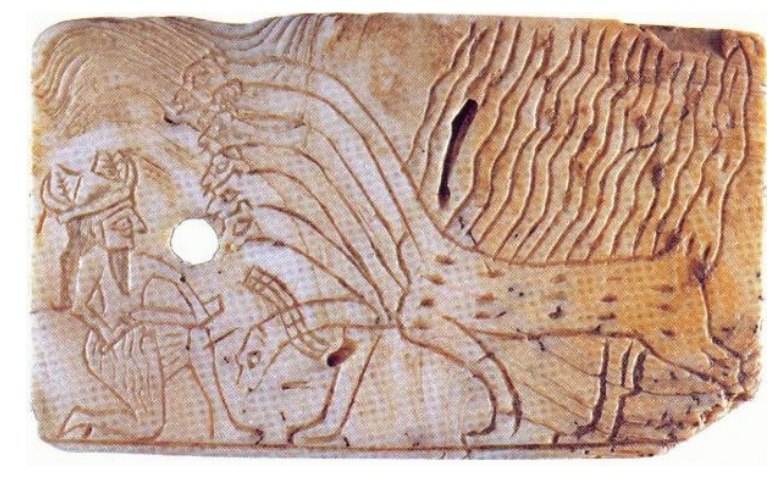 \\
\hline $\begin{array}{c}\text { Fonte: } \\
\text { Arte: Hans Sebald Beham, } 1545 \text { (B.102, P.100 } \\
\text { iv/iv). Detroit Institute of Arts (dia.org/art); } \\
\text { código de acesso: } 46.214 .\end{array}$ & $\begin{array}{c}\text { Fonte: } \\
\text { Museu das Terras Bíblicas, em Jerusalém } \\
\text { (BLMJ 2051). }\end{array}$ \\
\hline
\end{tabular}

\subsection{A Paleta de Narmer}

Descoberta em 1898 pelos arqueólogos britânicos James E. Quibell e Frederick W. Greene, em Hierakonpolis, no chamado Alto Egito, a chamada Paleta de Narmer é uma obra de arte egípcia e se encontra no Museu Egípcio do Cairo, medindo $64 \mathrm{~cm}$ x $42 \mathrm{~cm}$ (NAJOVITS, 2003, p. 160). Os egiptólogos Brier e Hobbs (2008, p. 202) afirmam que a Paleta deve ser o mais antigo "documento histórico da cultura universal”, depois das pinturas rupestres. Kleiner (2011, p. 55, 56) também afirma tratar-se de uma das "mais antigas obras de arte preservadas" e representa o “triunfo inevitável do deus-rei egípcio sobre seus inimigos”. Janson e Janson (2004, p. 49) também considera esta como "a mais antiga obra de arte histórica conhecida, sendo de 3150-3125 a.C." 
O tema central do texto pictórico é o rei egípcio Narmer dominando um rei inimigo, supostamente o governante egípcio vizinho. Cline e Rubalcaba (2005, p. 24) afirmam que o documento de fato conta a história da unificação do Egito sob um rei. "De um lado da paleta, Narmer usa a coroa branca do Alto Egito (sul), e do outro ele usa a coroa vermelha do Baixo Egito (norte). Ele foi o primeiro rei a governar sobre ambos".

Alguns argumentam que a unificação dos dois reinos egípcios somente ocorreu por volta no ano 3100 a.C. com o primeiro faraó, Menés I, que passou a utilizar uma única coroa que fundia as cores branca (Alto Egito) e vermelha (Baixo Egito). Menés não somente teria sido o primeiro faraó egípcio, mas também o responsável por fundar a primeira das 30 dinastias que governariam o país entre 3100 e 332 a.C. Narmer é considerado ser o mesmo lendário Menés (BREWER, 2012, p. 88).

Como abertura do texto pictórico, destaca-se uma espécie de cabeçalho, de ambos os lados com duas figuras divinas, o que atribui à paleta um tom religioso e cerimonial. As duas faces humanas com características bovinas, que, segundo Shahawy (2005, p. 21), representam a deusa Hathor que é uma das mais antigas representações de um deus com formas humanas. Kleiner $(2011,56)$ observa que as faces são femininas, as quais às vezes identificavam a deusa celestial Bat. Cline e Rubalcaba (2005, p. 24) lembram que os antigos egípcios pensavam que a deusa Hathor fosse a mãe do rei e normalmente a desenhavam com seus "chifres enrolados para a parte interna”. Entre as duas cabeças da deusa há um hieróglifo com o nome de Narmer, como se a deusa estivesse outorgando a vitória ao rei.

A paleta é esculpida de ambos os lados e tem a forma de um escudo. Há três registros principais na primeira página da paleta, abaixo das faces bovinas. O tema principal desse lado é a supremacia de Narmer, que aparece em pé em dimensões bem maiores que os demais personagens, indicando seu poder e autoridade como rei 
e deus. Em tamanho menor, atrás do rei está um servo com "suas sandálias e um jarro para purificação" (SHAHAWY, 2005, p. 21). À sua frente está um prisioneiro ajoelhado, prestes a ser atingido pelo rei. Um par de símbolos aparece ao lado de sua cabeça, talvez indicando seu nome ou a região de origem.

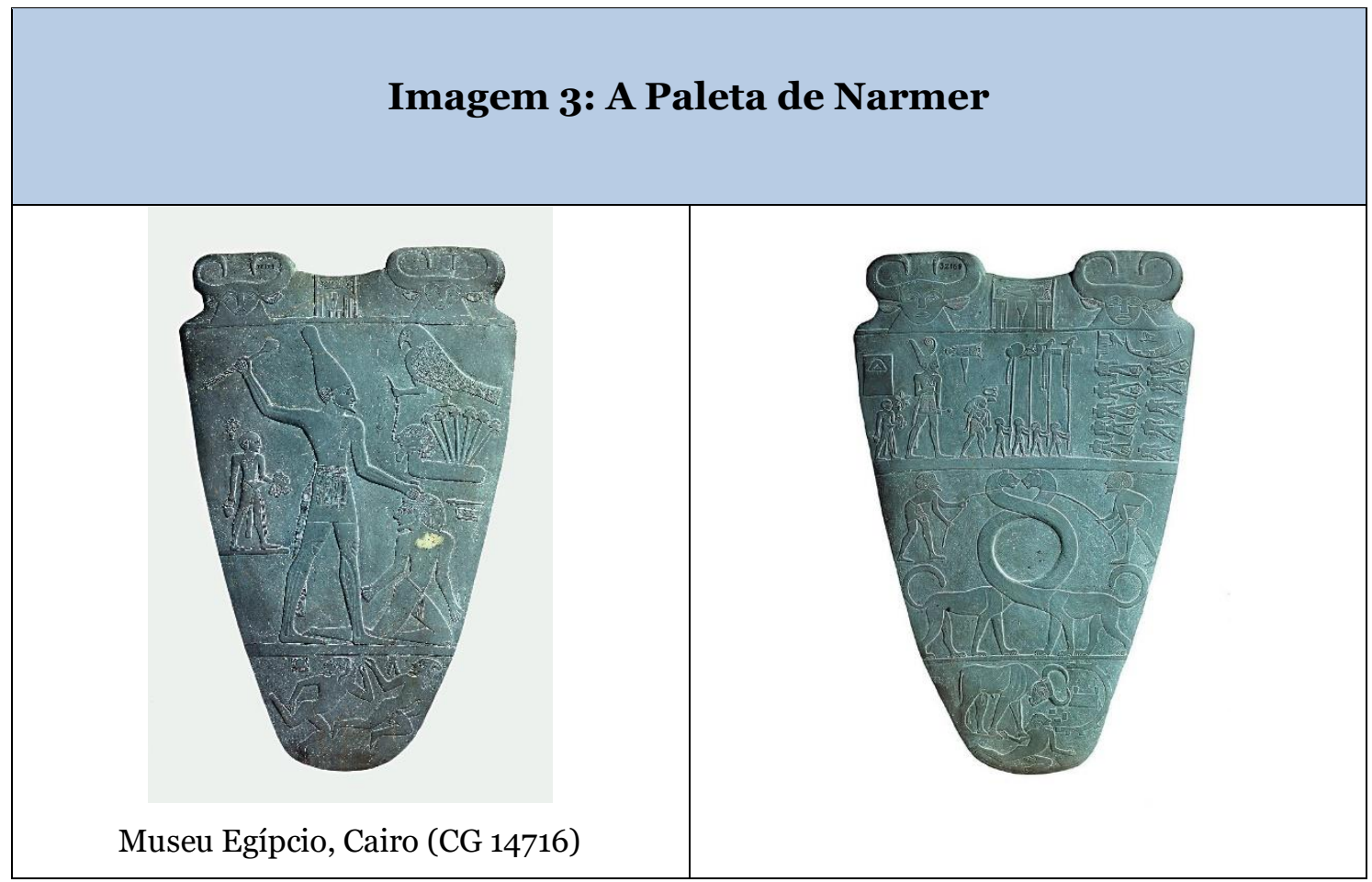

Fonte: ANCIENT HISTORY ENCYCLOPEDIA

No segundo registro, acima do prisioneiro está um falcão, representando o deus celestial do Alto Egito, chamado Hórus, o "protetor do rei” (KLEINER, 2011, p. 56), empoleirado sobre um conjunto de seis hastes de papiro, as quais emergem das costas de um símbolo semelhante a uma serpente com cabeça humana, representando o Baixo Egito, agora sob domínio de Narmer. Em suas garras, com um braço humano, o falcão segura um tipo de corda com a qual prende pelo nariz a cabeça da serpente, indicando estar subjugada. "O paralelo é claro: Hórus e Narmer são os mesmos personagens; ambos são deuses triunfantes sobre seus inimigos” 
(JANSON; JANSON, 2004, p. 49). Cline e Rubalcaba (2005, p. 25) destacam que o rei está com um rabo de touro, o que indica que ele é tão forte quanto esse animal.

Najovits (2003, p. 160) diz que este registro com o falcão Hórus com um braço humano, segurando pelo nariz a cabeça "barbuda", ligada a um corpo de serpente em cujas costas há seis papiros, "indica que a terra do papiro, o Baixo Egito, TaMehu, e seu povo têm sido conquistados, e que Hórus está entregando o Baixo Egito ao rei Narmer, com a coroa branca do Alto Egito”.

Para alguns, as seis hastes de papiros emergindo das costas do símbolo tipo serpente podem ser uma maneira de quantificar os inimigos conquistados, nesse caso 6 mil, pois a haste de papiro era o símbolo para mil. Porém, a figura de Narmer segurando pela cabeça o inimigo derrotado está em exato paralelo ao falcão que segura a figura tipo serpente pela cabeça. Esse paralelo produz o sentido de que o símbolo tipo serpente com sete cabeças representa o poder espiritual do Baixo Egito que tem sido subjugado pelo poder espiritual do Alto Egito, representado pelo falcão Hórus. Além disso, no lado inverso da paleta há uma representação de pessoas/guerreiros conquistados em duas fileiras de cinco elementos. Nesse caso, o número sete, resultante da soma da cabeça da serpente mais as seis hastes em suas costas, pode representar o poder espiritual, enquanto o número dez dos soldados mortos representaria os inimigos humanos abatidos. Essa linguagem pode representar a vitória sobre criaturas sinistras, sendo apropriado representar o inimigo conquistado, na figura de deuses igualmente subjugados.

De fato, como um texto da cultura, a paleta vai além de narrar um fato histórico. Cline e Rubalcaba (2005, p. 26) afirmam que a obra "mostra Narmer vitorioso sobre as forças do mal”, e que nesta arte ele é retratado como o conquistador do "caos". O artista contou uma história política, mas atribuindo-lhe um sentido mitológico, inserindo-a no reino dos deuses. O desenho mostra Narmer sem sandálias, um sinal de que o local em que está é santo, o que acentua o caráter religioso da obra (JANSON; JANSON, 2004, p. 49). Honour e Fleming (2005, p. 54) 
dizem que a paleta era para ser "lida" como uma declaração factual do poder de Narmer em derrotar seus inimigos. Porém, assim como outras obras da arte egípcia, ela é "simbólica" e representa acontecimentos maiores que os eventos em questão.

No segundo lado, a Paleta de Narmer acrescenta mais detalhes à importante conquista. No primeiro registro, logo abaixo das duas faces bovinas, o rei é seguido pelo portador de sandálias e a sua frente estão dois vizirs e quatro pessoas carregando estandartes, numa espécie de procissão para posse do território conquistado. A vitória é representada na imagem de dez inimigos decapitados com suas cabeças colocadas entre as pernas, indicando completa subjugação e humilhação. Acima deles há uma representação de um pássaro, barco e arpão, sugerindo livre acesso às cidades e regiões conquistadas (SHAHAWY, 2005, p. 21).

No segundo registro, abaixo da procissão, dois homens seguram cordas amarradas aos pescoços estendidos e entrelaçados de dois serpóparos frente a frente. O serpóparo é uma criatura mitológica resultado da junção de "serpente" e "leopardo". O Alto e o Baixo Egito adoravam deusas representadas por leoas, indicando a capacidade de proteção dessas divindades. Os pescoços entrelaçados dos serpóparos podem representar a unificação do Egito. Os dois personagens segurando as cordas têm a mesma forma, o que sugere um só governo sobre ambas as regiões. "Esta pode ser uma representação simbólica da unidade entre as regiões sul e norte do país, ou pode igualmente simbolizar o fim do estado de guerra entre o norte e o sul” (SHAHAWY, 2005, p. 21).

Curiosamente, a imagem de dois animais tipo felino como símbolos dos dois Egito pode ser vista como uma representação bastante antiga de poderes políticos constituídos por meio de metáforas de animais ou bestas. Enquanto o falcão e as faces bovinas são tidos como materialização de deuses, os dois serpóparos são claramente metáforas para nomear poderes terrenos.

Desta forma, a Paleta de Narmer, um documento muito antigo da cultura universal, evidencia o emprego de metáforas de animais para representar um país 
opositor ou o poder político e religioso do mesmo. Além disso, mais importante ainda é possibilidade da representação desses poderes pela metáfora de um monstro de sete cabeças. Tanto essa figura de sete cabeças quanto a figura de um animal como metáfora para poderes políticos fazem da Paleta de Narmer um importante documento da cultura antiga no estudo da representação metafórica de poderes opositores repercutida no texto bíblico.

Como um texto da cultura, a Paleta de Narmer é parte integrante da semiosfera, dentro da qual ela também exerce uma função modelizadora, pois se acha entrecruzada com outros textos da cultura universal. Os sentidos produzidos por suas metáforas migram para outras culturas no processo dinâmico de transmissão de linguagens e sentidos dentro da semiosfera.

\subsection{O Cilindro de Tell Asmar}

A imagem de um monstro de sete cabeças é também atestada em antigos textos sumerianos, babilônicos e egípcios (JOHNSON, 1981, p. 524). Wallace (1948, p. 68) diz que o Leviatã, um dos principais monstros de sete cabeças, é parte do tema do dragão na mitologia encontrada em diversas religiões antigas.

Um documento que tem exercido importante papel no estudo da metáfora do dragão de sete cabeças é o famoso selo cilíndrico encontrado na Mesopotâmia, em Tell Asmar, antiga Eshnunna, cerca de $80 \mathrm{~km}$ a noroeste da atual Bagdá. Foi datado do ano 2200 a.C. e publicado inicialmente por Henry Frankfort, em 1933. O cilindro acadiano feito em pedra está no Instituto Oriental, na Universidade de Chicago, nos Estados Unidos. Rendsburg (1984, p. 448) diz que "um dos maiores valores da arte antiga, além de seu significado enquanto arte, é iluminar textos antigos, especialmente os míticos”. Nisso o cilindro de Tell Asmar é bastante relevante. 


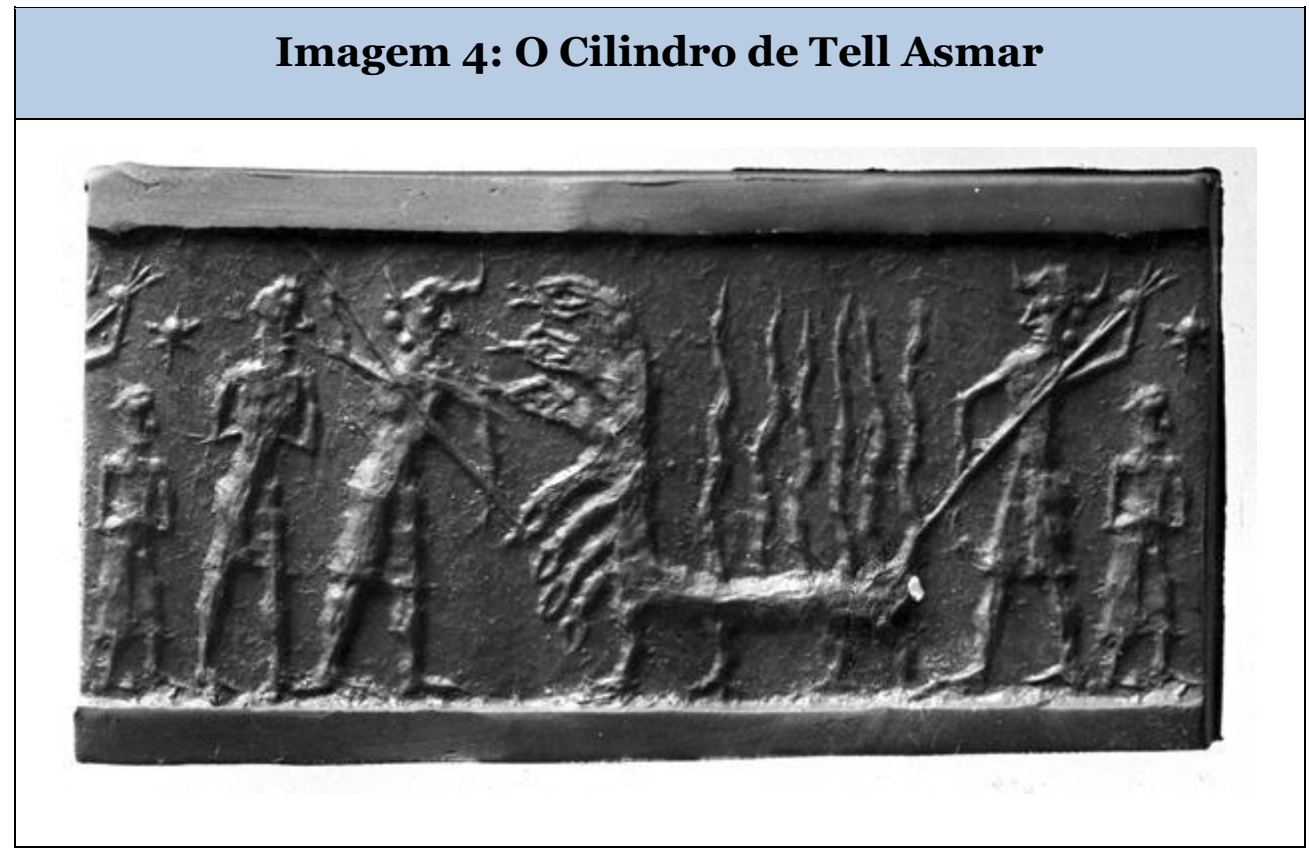

Fonte: FRANKFORT, 1955.

O tema do cilindro é o mesmo do deus (herói) que derrota o monstro de sete cabeças. Esse tema ocorre em Ugarit, onde Baal vence o Lotan-Yamm de sete cabeças, e na Grécia onde Hércules combate a hidra de múltiplas cabeças (RENDSBURG, 1984, p. 448). Frankfort comentou sua descoberta com a seguinte afirmação: "O Leviatã está demonstrado, através dos paralelos nos textos de Ras Shan-Ra, por ter sete cabeças" (cf. RENDSBURG, 1984, p. 449). Wallace (1948, p. 63) afirma que o Leviatã é uma serpente de sete cabeças ligada às águas e que esse conhecimento tem vindo do "material de fundo provido pelos textos de Ras ShanRa”. Para ele, o conceito do Leviatã "está na base do uso da metáfora da besta do Apocalipse".

O cilindro de Tell Asmar mostra um dragão de sete cabeças sendo subjugado por dois personagens, possivelmente um só, visto que ambas têm o mesmo capacete com chifres e usam o mesmo saiote até os joelhos, e as lanças são seguradas na mesma posição (RENDSBURG, 1984, p. 451). Há também mais dois personagens à esquerda do selo, um deles com um calendário na mão, olhando para o céu. Rendsburg (1984, p. 452) considera que o selo é mais um exemplo das narrativas 
contínuas ou de sequências lineares da arte antiga, que representam um evento paradigmático permanente. "Assim, o relacionamento entre o selo e os mitos, especialmente sua versão ugarítica, é bem forte”.

Que deus ou rei estaria representado no cilindro de Tell Asmar é uma questão importante na tentativa de relacionar o selo com a metáfora bíblica da besta de sete cabeças. De igual importância é saber o que ou quem está representado no monstro de sete cabeças. Barker (2014, p. 134) argumenta haver razões para comparar os dois heróis/deuses do selo de Tell Asmar com Ningirsu, uma divindade sumeriana. "O capacete com chifres é característico de Ningirsu, como se observa no mito sumeriano Lugal-e”. Ele diz que esta descrição de Ningirsu como um guerreiro ocorre somente dez linhas após a menção do combate de Ningirsu contra a serpente de sete cabeças. "O tablete sumeriano também retrata Ningirsu usando um capacete com chifres quando ele combate o leão de sete cabeças". Além disso, o Lugal-e deixa claro que "a lança de Ningirsu era uma de suas armas características”.

Barker (2014, p. 137) diz ainda que leões são frequentemente associados a Ningirsu. Ele acredita que essas associações podem resultar do centro do culto de Ningirsu, localizado bem próximo à região com grande população de leões. “A associação a leões, em Girsu, pode explicar por que os Cilindros Gudea interpretam a besta de sete cabeças como um leão em vez de uma serpente. É possível que a serpente de sete cabeças ou dragão tenha sido reinterpretada como um leão [em Lugal-e] de sete cabeças por causa do culto de Girsu”. Além disso, Barker afirma que o Cilindro Gudea e o Lugal-e indicam que Ningirsu era conhecido por ter matado um monstro de sete cabeças. As três fontes são do terceiro milênio. Portanto, Barker conclui que "a interpretação mais natural do selo cilíndrico de Tell Asmar é que ele é uma representação da batalha de Ningirsu com o 'monstro derrotado' de sete cabeças”. Para ele, um ponto final que corrobora essa interpretação é a identidade das duas figuras auxiliares no selo. 
Tendo identificado a batalha de Ningirsu contra o monstro derrotado como a imagem principal de selo, Barker (2014, p. 137) afirma que a figura menor dos dois outros personagens do selo provavelmente seja Nidaba, "segurando um quadro astrológico e consultando as estrelas em favor de Ningirsu". A figura astral acima deste é "o deus Ningishzida mostrada aqui como o sol, e a divindade à direita de Nidaba é Nindub, desenhando um templo para Ningirsu”. Ele diz que todos esses personagens aparecem exatamente dessa maneira, estando próximo a Ningirsu, no chamado "Sonho de Gudea".

Na tentativa de interpretar o conteúdo do selo, Barker diz ser possível que o monstro derrotado de Tell Asmar, sendo o Leviatã ou outro qualquer monstro de múltiplas cabeças, seja considerado como o antagonista principal de uma divindade maior. A função desse monstro seria tentar evitar que a divindade maior estabelecesse seu domínio cósmico, com a construção de um templo. Ele argumenta que, no caso do Antigo Testamento, o estabelecimento do templo cósmico de Yahweh, no monte Sião, surge como um tema coerente (cf. Is 2; 6). Esse sentido também é produzido em narrativas escatológicas, sejam do Antigo Testamento ou no Apocalipse (cf. Is 27; 4 Esdras 6:49-52; Ap 12; 21). Com base nisso, Barker (2014, p. 169) conclui que "a criatura de Tell Asmar, a lista dos monstros derrotados mencionada no Lugal-e, a lista de monstros dos tabletes de Ugarit, e o Leviatã morto no material bíblico, todos apontam para uma ideia antiga bastante difundida no Oriente Médio de que um dragão de múltiplas cabeças (simbolizando o mal, forças antagônicas no cosmos) era derrotado pela divindade maior antes de esta divindade construir seu templo [ou domínio] cósmico”.

Seria de fato o Leviatã acadiano o antecedente do Leviatã bíblico e da besta de sete cabeças? Apesar de haver diversos mitos e tradições acerca de dragões e criaturas tipo serpente, nos textos da Mesopotâmia, os pesquisadores debatem as evidências para juntar estas tradições com o texto bíblico. Barker (2014, p. 134) considera falsa a equivalência entre o monstro de sete cabeças do selo de Tell Asmar e o Leviatã da Bíblia “com base no aspecto das sete cabeças”. No entanto, ele diz que 
pode haver ainda uma conexão "indireta entre o selo de Tell Asmar e o Leviatã via o material de Ugarit”. Nesse caso, uma migração da metáfora ocorreu entre esses textos, mas tendo como mediação o material de Ugarit. Para Wallace (1948, p. 64), o emprego da metáfora do Leviatã no Salmo 74, embora seja um definitivo empréstimo da mitologia cananeia, e talvez haja algum relacionamento com a mitologia babilônica, "os israelitas não emprestaram qualquer ideia fundamental acerca de Deus destas duas fontes”. Eles tomaram essas metáforas e as aplicaram a seu esquema monoteísta.

Johnson (1981, p. 524) propõe que, ao empregar uma imagem da mitologia, “os hebreus não estavam necessariamente endossando a figura mitológica, que é apenas uma lenda baseada em uma visão dualista e maniqueísta”. Nas mitologias antigas, "as forças do bem e do mal batalhariam indefinidamente ao longo de eras sem fim". Para Johnson (1981, p. 524), os profetas bíblicos na verdade "desmitologizaram os mitos do monstro marinho ao retratar a vitória do Deus de Israel sobre as forças demoníacas do mal que em diversas manifestações tentavam destruir o povo de Deus".

\section{Considerações finais}

As semelhanças entre as figuras monstruosas das narrativas antigas de um combate de personagens divinos com esses monstros mostram que o texto bíblico é produzido dentro da realidade cultural e linguística em que seus autores estão inseridos. $\mathrm{O}$ contato dos autores do texto bíblico com essas narrativas é evidenciado nessas semelhanças. No entanto, apesar de o texto bíblico ser produzido como um texto da cultura, é preciso considerar as hipóteses acerca da origem comum dessas narrativas.

Se consideramos as tradições antigas como textos da cultura, entendemos que as metáforas empregadas nas mesmas tendem a se disseminar em outras culturas na medida em que os textos dessas culturas retratem realidades paralelas 
ou semelhantes. A metáfora de um monstro de sete cabeças que se opõe ao projeto cósmico de um deus e que é em seguida derrotado para a conclusão do projeto divino parece ter se tornado num arquétipo, e as linguagens para expressá-lo tendem igualmente a serem compartilhadas, apesar de cada cultura ter um sistema conceitual próprio, uma visão cósmica e um conceito particular de seus deuses.

Em seu estudo dos mitos de combate, com os quais o Apocalipse de João mantém semelhanças, Collins (2001, p. 57, 58) afirma que essas narrativas apresentam formas arquetípicas de "longa história” na cultura da Mesopotâmia. Ela conclui que os diversos mitos de combate em circulação no primeiro século evidenciam um "modelo comum", o que indica que "derivam de um protótipo comum”. Assim, os arquétipos encadeadores desses textos apontam para uma narrativa comum entre eles.

Por sua vez, Meletínski (2002, p. 157-158) também defende a ideia de uma matriz arquetípica para as figuras mitológicas a qual se desdobra e sofre variações e contextualizações ao longo de uma cadeia de textos. Segundo ele, tanto no mito como no epos heroico, na lenda e no conto de magia, todos igualmente ricos em conteúdo arquetípico, os arquétipos evidenciam "transformações". Porém, mesmo no caso dessas transformações, “o arquétipo originário transparece bastante claramente”, como que permanecendo "depositado no nível profundo da narrativa". Ele considera os arquétipos como "elementos temáticos" que se constituem em "unidades" de uma "linguagem temática" da literatura universal. Para ele, nos estágios iniciais, esses esquemas se mostram uniformes e, em estágios mais tardios, apresentam variações, as quais, no entanto, se bem analisadas, mostram-se como "transformações originais de alguns elementos iniciais" ou primordiais (2002, p. 19).

Nessa linha de pensamento, Lotman e Mints (1996, p. 194) afirmam que o texto mitológico se reproduz em textos posteriores como na imagem de um "repolho", onde "cada folha repete com certas variações todas as demais, e a repetição infinita de um mesmo núcleo de sujeito profundo se enrola num todo 
aberto a novos crescimentos". Nesse sentido, um tema como o do "combate" (COLLINS, 2001) ou do "herói" (MELETÍNSKI, 2002) permanece como uma matriz arquetípica, mas sujeito a variações e adaptações nos diferentes contextos de sua reprodução.

Assim, os arquétipos como elementos vinculadores dos textos da cultura de natureza religiosa e mitológica evidenciam não só o papel da memória e das linguagens da cultura na produção desses textos como apontam para um texto ou narrativa original comum, na origem dos mesmos. Esse texto primordial sofre transformações e adaptações nas diferentes culturas em que são reproduzidos. No entanto, os arquétipos são preservados, como diz Meletínski, no "nível profundo da narrativa”.

\section{REFERÊNCIAS}

ANCIENT HISTORY ENCYCLOPEDIA. A Paleta de Narmer. Disponível em: <http://www.ancient.eu/image/4526/>. Acesso em: 12 dez. 2017.

AUNE, David E. Word Biblical Commentary. Revelation 1-5. Dallas, TX: Word Books, 1997.

BARKER, William D. Isaiah's Kingship Polemic: An Exegetical Study in Isaiah 24-27. Tübingen, Alemanha: Mohr Siebeck, 2014.

BEHAM, Hans Sebald. Hercules Slaying the Hydra. 1545. Disponível em: <https://www.dia.org/art/collection/object/hercules-slaying-hydra-34380>. Acesso em: 12 dez. 2017.

BREWER, Douglas, J. The Archaeology of Ancient Egypt: Beyond Pharaohs. New York: Cambridge University Press, 2012.

BRIER, Bob; HOBBS, Hoyt. Daily Life of the Ancient Egyptians. Westport, CT: Greenwood Press, 2008.

CLINE, Eric H.; RUBALCABA, Jill. The Ancient Egyptian World. New York: Oxford University Press, 2005.

COHEN, Jeffrey Jerome. Monster Culture (Seven Theses). Monster Theory: Reading Culture. Minneapolis: University of Minnesota Press, 1996. p. 3-25. 
COLLINS, Adela Y. The Combat Myth in the Book of Revelation. Eugene, OR: Wipf and Stock Publishers, 2001.

FORD, Micheal W. Sebitti: Mesopotamin Magick and Demonology. Springs, TX: Succubus, 2016.

FRANKFORT, Henry. O Cilindro de Tell Asmar. Oriental Institute, University of Chicago (IM15618), 1955.

HONOUR, Hugh; FLEMING, John. A World History of Art. Londres: Laurence King Publishing, 2005.

JANSON, H.W.; JANSON, Anthony F. History of Art: The Western Tradition. Upper Saddle River: Pearson, 2004.

JOHNSON, Alan F. “Revelation”. Ed. Frank E. Gaebelein, The Expositor's Bible Commentary. Grand Rapids, MI: Zondervan, 1981.

JOHNSSON, William G. Apocalíptica bíblica. In: DEDEREN, Raoul (Ed.). Tratado de Teologia Adventista do Sétimo Dia. Ed. Raoul Dederen. Tatuí, SP: Casa Publicadora Brasileira, 2011. p. 870-903.

KISTEMAKER, Simon J. New Testament Commentary: Exposition of the Book of Revelation. Grand Rapids, MI: Baker Academic, 2001.

KRISTEVA, Julia. Introdução a Semanálise. São Paulo Perspectiva, 1969.

KLEINER, Fred S. Gardner's Art through the Ages: A Global History. 13. ed. Vol. 1. Boston, MA: Wadsworth, 2011.

LAKOFF, George; JOHNSON, Mark. Metaphors We Live By. Londres: University Chicago Press, 2003.

LOTMAN, Yuri. Universe of the Mind: A Semiotic Theory of Culture. Trad. Ann Shukman. Indianápolis: Indiana University Press, 2000.

LOTMAN, Iuri. La semiosfera: semiótica de la cultura e del texto. Tradução de Desiderio Navarro. Madri: Frónesis Cátedra/Universitat de Valencia, 1996.

LOTMAN, Iuri; MINTS, Zara G. Literatura e mitologia. In: LOTMAN, Iuri. La semiosfera: semiótica de la cultura e del texto. Tradução de Desiderio Navarro. Madri: Frónesis Cátedra/Universitat de Valencia, 1996. p. 190-213.

MELETÍNSKI, E. M. Os arquétipos literários. 2 ed. Cotia, SP: Ateliê Editorial, 2002.

MOUNCE, Robert. The Book of Revelation. Grand Rapids, MI: Eerdmans, 1998. 
NAJOVITS, Simson. Egypt: Trunk of the Tree. New York: Algora Publishing, 2003.

RENDSBURG, Gary A. "UT 68 and the Tell Asmar Seal”. Orientalia, Lisboa, v. 53, n. 4, p. 448-452, 1984.

ROMAN, Luke; ROMAN, Monika. Encyclopedia of Greek and Roman Mythology. New York: Facts on File, 2010.

SHAHAWY, Abeer el. The Egyptian Museum in Cairo: A Walk through the Alleys of Ancient Egypt. Cairo: Farib Atiya Press, 2005.

SLOAN, Robert B.; NEWMAN, Carey C. "Ancient Jewish Hermeneutics”. In: CORLEY, Bruce; LEMKE, Steve W.; LOVEJOY, Grant I. (Ed.). Biblical Hermeneutics: A Comprehensive Introduction to Interpreting Scripture. 2. ed. Nashville, TN: Broadman \& Holmas, 2002. p. 23-39.

WALLACE, Howard. Leviathan and the Beast in Revelation. The Biblical Archaeologist, Boston, v. 11, n. 3, p. 61-68, setembro de 1948. 